\title{
Compactação de um Solo Submetido ao Tráfego do Harvester e do Forwarder na Colheita de Madeira
}

\author{
Eduardo da Silva Lopes ${ }^{1}$, Diego de Oliveira ${ }^{1}$, \\ Carla Krulikowski Rodrigues ${ }^{1}$, Carlos Henrique Drinko ${ }^{1}$
}

${ }^{1}$ Departamento de Engenharia Florestal, Universidade Estadual do Centro-Oeste - UNICENTRO, Irati/PR, Brasil

\begin{abstract}
RESUMO
Este trabalho avaliou a compactação do solo submetido ao tráfego do harvester e do forwarder na colheita de madeira em povoamentos de Pinus taeda L. Os dados foram coletados em uma empresa florestal localizada no município de Campo do Tenente, estado do Paraná. A avaliação da compactação foi feita por meio dos parâmetros físicos densidade do solo, porosidade total, porosidade de aeração e resistência do solo à penetração em três níveis de profundidades: 0 a $15 \mathrm{~cm}$, 15 a $30 \mathrm{~cm}$ e 30 a $50 \mathrm{~cm}$. Os dados foram submetidos à análise de variância e as médias comparadas pelo teste de Tukey ao nível de $95 \%$ de probabilidade. O tráfego das máquinas provocou uma maior compactação nas camadas superficiais do solo, sendo que após o tráfego do forwarder houve um aumento no incremento da resistência do solo à penetração, em relação à testemunha, da ordem de 151,4\%, com valor médio de 1,76 Mpa. Não houve diferença estatística significativa nas propriedades do solo devido ao tráfego das máquinas de colheita no sistema de toras curtas.
\end{abstract}

Palavras-chave: máquinas florestais, compactação, meio ambiente.

\section{Compaction of a Soil Subjected to the Traffic of Harvesters and Forwarders During Wood Harvesting}

\begin{abstract}
This study evaluated the compaction of a soil submitted to the traffic of wood harvesting machines in Pinus taeda L. stands. The data were obtained from a forest company located in the municipality of Campo do Tenente, Parana state, Brazil. Soil compaction was evaluated by determining the following physical parameters: bulk density, particle density, total porosity, aeration porosity, and soil penetration resistance at three depths: 0 to 15,15 to 30 , and 30 to $50 \mathrm{~cm}$. The data were submitted to analysis of variance, and means were compared by the Tukey test at $5 \%$ probability level. The results show that the traffic of forest machines caused greater compaction in the soil surface layers after the traffic of forwarders, with an increase of $151.4 \%$ in the increment of soil penetration resistance compared with the control, with a mean value of $1.76 \mathrm{MPa}$. We conclude that there are no statistically significant differences in soil properties due to machine traffic in the cut-to-length system.
\end{abstract}

Keywords: forest machines, compaction, environment. 


\section{INTRODUÇÃO}

A intensificação da mecanização nas atividades de colheita da madeira tem acarretado no aumento do tráfego de máquinas de grande porte e potência, contribuindo para o incremento da compactação e o desequilíbrio das características físicas, químicas e biológicas do solo (Lopes et al., 2006).

Atualmente, na colheita de madeira, predominam dois sistemas: toras curtas (cut to length) e árvores inteiras (full tree). O primeiro é caracterizado pelo uso dos tratores florestais harvester e forwarder, que acarretam menor impacto ambiental devido à baixa exportação de nutrientes e menor compactação do solo, porém acarreta em maiores custos operacionais. Já o segundo, caracterizado pelos tratores florestais feller buncher, skidder e harvester (processador), apesar de apresentar menores custos operacionais, causa maiores danos ambientais, principalmente em termos de compactação do solo.

A compactação do solo consiste na agregação das partículas, reduzindo o volume por elas ocupado (Camargo, 1983). Trata-se da tensão aplicada sobre o solo e mudanças em termos de aumento da densidade, decréscimo no volume de macroporos e na infiltração, com movimento interno de água mais lento e maior resistência mecânica ao crescimento das raízes. Soane \& Van Ouwerkerk (1994) dizem que a compactação é o processo de aumento na densidade aparente do solo, com incremento da resistência à penetração e redução na porosidade total e permeabilidade.

A compactação do solo nas áreas de colheita de madeira é influenciada por diversos fatores, destacando-se: tipo de solo; teor de matéria orgânica; teor de umidade; resíduos sobre o terreno; número de passadas, tipos de rodados e das máquinas.

Segundo Reichert et al. (2007), os efeitos da matéria orgânica são mais pronunciados em solos arenosos, mais susceptíveis à alteração de sua estrutura, porém de recuperação mais rápida em relação aos solos argilosos. Isso se deve ao fato de a matéria orgânica reter maior quantidade de água, dificultando a formação de películas de água sobre a superfície dos grãos de areia.

A umidade controla a quantidade de deformação do solo, atuando como lubrificante entre as partículas e permitindo o deslocamento entre elas, situação favorecida pelo aumento da umidade. Esse processo continua até que a água sature praticamente todos os poros do solo, no qual, a partir desse momento, a cada incremento no conteúdo de água não corresponderá um incremento na densidade (Silva et al., 2000). Dias \& Pierce (1996) consideraram que o teor de água no momento em que o solo está sendo compactado tem grande influência na redução e redistribuição do espaço poroso, sendo que solos com baixos teores de água têm maior resistência à compactação.

Em relação à camada de resíduos da colheita de madeira sobre o terreno, Seixas et al. (1995) detectaram reduções da ordem de $40 \%$ no incremento da densidade de um solo durante o tráfego de um forwarder sobre uma camada de resíduos. Seixas et al. (1998) observaram uma redução da compactação nos tratamentos com cobertura com carga de área de 5 e $16 \mathrm{~kg} \mathrm{~m}^{-2}$ proporcionando uma redução média de 56\% na densidade aparente.

Seixas \& Souza (2007), estudando a influência do número de passadas das máquinas na compactação do solo verificaram que o efeito do tráfego foi maior após as primeiras passadas, sendo que $80 \%$ do incremento da compactação ocorreu após as cinco primeiras passadas de um forwarder. Já Fernandes et al. (1997) constataram que o número de passadas dos rodados do forwarder na compactação de um solo ocorreu após a primeira passada, voltando a ocorrer após a nona.

Por fim deve-se ressaltar que o tipo de máquina utilizada na colheita de madeira pode causar a compactação do solo. Lanford \& Stokes (1995) observaram que o skidder causou $50 \%$ a mais de alterações visíveis no solo em relação ao forwarder. Tal afirmação é reforçada por Fenner (2002), que constatou que o tráfego do feller buncher e do skidder afetou praticamente toda a área do talhão, mesmo o solo tendo sido trafegado apenas uma vez, enquanto o tráfego do harvester e do forwarder ficou concentrado nos ramais de extração de madeira. Dias et al. (2003) dizem ainda que o harvester e o forwarder podem causar uma maior degradação na estrutura do solo devido aos impactos ocorrerem de forma sistemática e abrangendo posições definidas, enquanto no feller buncher e no skidder eles ocorrem de forma aleatória e abrangendo grande área do talhão.

Objetivou-se neste trabalho avaliar os níveis de compactação causada pelo tráfego dos tratores florestais harvester e forwarder na colheita de madeira de Pinus taeda L., de forma a subsidiar o planejamento das operações para redução de impactos no meio ambiente e a sustentabilidade da produção florestal. 


\section{MATERIAL E MÉTODOS}

\section{1. Área de estudo}

O trabalho foi realizado nas áreas de colheita de madeira em povoamentos de Pinus taeda L. de uma empresa florestal localizada no município de Campo do Tenente, estado do Paraná, entre os paralelos $25^{\circ} 58^{\prime} 40^{\prime \prime}$ S e $49^{\circ} 40^{\prime} 58^{\prime \prime}$ W.

De acordo com o sistema de classificação de Köeppen, o clima da região é classificado como subtropical úmido mesotérmico $(\mathrm{Cfb})$, com temperatura média anual de $17^{\circ} \mathrm{C}$ e umidade relativa do ar em torno de $82,5 \%$, altitude de $802 \mathrm{~m}$ e relevo classificado como suave a ondulado.

O solo da área em estudo foi classificado como um Cambissolo Háplico, de textura média, com teores médios de $38,2 \%$ de areia, $30,5 \%$ de silte e $31,3 \%$ de argila, com teor médio de umidade de $17,7 \%, 16,2 \%$ e $18,7 \%$ nas profundidades de 0 a $15 \mathrm{~cm}, 15$ a $30 \mathrm{~cm}$ e 30 a $50 \mathrm{~cm}$, respectivamente. A análise granulométrica e da umidade gravimétrica do solo foram realizadas por meio de metodologia proposta pela Embrapa (1997) e seus valores serviram para melhor caracterizar o solo da área em estudo (Tabela 1).

Tabela 1. Valores médios da granulometria e umidade gravimétrica do solo estudado.

Table 1. Mean values of grain size and humidity gravimetric soil studied.

\begin{tabular}{ccccc}
$\begin{array}{c}\text { Profundidade } \\
(\mathbf{c m})\end{array}$ & Areia & $\begin{array}{c}\text { Argila } \\
\text { (kg.kg-1) }\end{array}$ & & $\begin{array}{c}\text { Ug } \\
\left(\mathbf{k g}^{-} \mathbf{k g}^{-1}\right)\end{array}$ \\
\hline 0 a 15 & 0,313 & 0,269 & 0,319 & 0,177 \\
15 a 30 & 0,386 & 0,296 & 0,318 & 0,162 \\
\hline 30 a 50 & 0,348 & 0,375 & 0,278 & 0,187 \\
Média & 0,349 & 0,313 & 0,305 & 0,175 \\
\hline
\end{tabular}

Ug: umidade gravimétrica. Fonte: elaborada pelos autores.

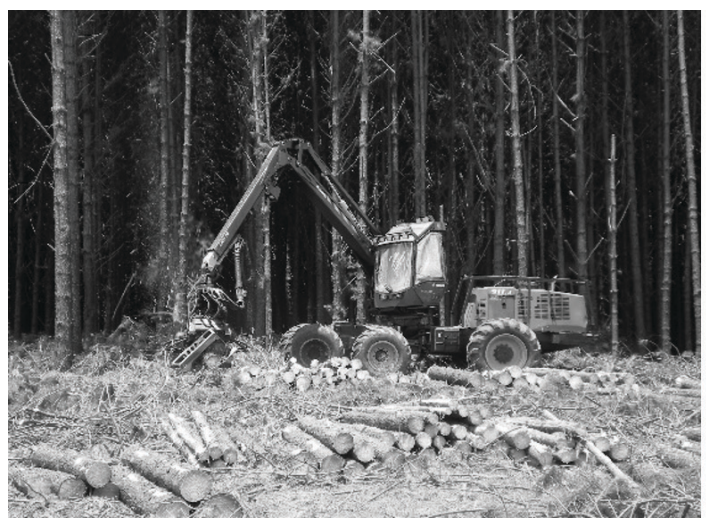

\subsection{Sistema de colheita estudado}

O sistema de colheita de madeira utilizado pela empresa era de Toras Curtas (Cut-to-length), conforme mostrado na Figura 1.

$\mathrm{O}$ corte das árvores foi realizado por um trator florestal harvester da marca Valmet, modelo 911.4, com potência nominal do motor de $228 \mathrm{HP}$, peso de 17,7 t e rodados de pneus. O harvester trafegava cortando e processando as árvores em toras com diferentes sortimentos destinados para uso em serraria e produção de celulose, ficando os resíduos da colheita de madeira dispostos sobre as trilhas de tráfego das máquinas. A extração da madeira foi realizada por um forwarder da marca Valmet, modelo 890.3, com potência nominal do motor de $204 \mathrm{HP}$, peso de 19,1 te rodados de pneus. O forwarder trafegava pela mesma trilha de tráfego do harvester.

\subsection{Coleta de dados}

A coleta dos dados foi realizada durante as operações de colheita da madeira, sem interferir no ritmo normal de trabalho da empresa. A amostragem foi feita por meio da instalação de três parcelas no interior do talhão, com dimensões de $5 \times 50 \mathrm{~m}$, distribuídas de forma aleatória sobre as trilhas de tráfego das máquinas.

Em cada parcela foram coletadas as amostras de solo e de penetrometria em quatro pontos dispostos sobre as linhas dos rodados das máquinas, nas profundidades de 0 a $15 \mathrm{~cm}, 15$ a $30 \mathrm{~cm}$ e 30 a $50 \mathrm{~cm}$ e coletadas nos seguintes períodos: antes do tráfego das máquinas de colheita de madeira (testemunha) (AT), após o tráfego do harvester (HV) e após o tráfego do forwarder (FW).

A compactação foi avaliada por meio dos seguintes parâmetros físicos do solo: Umidade gravimétrica

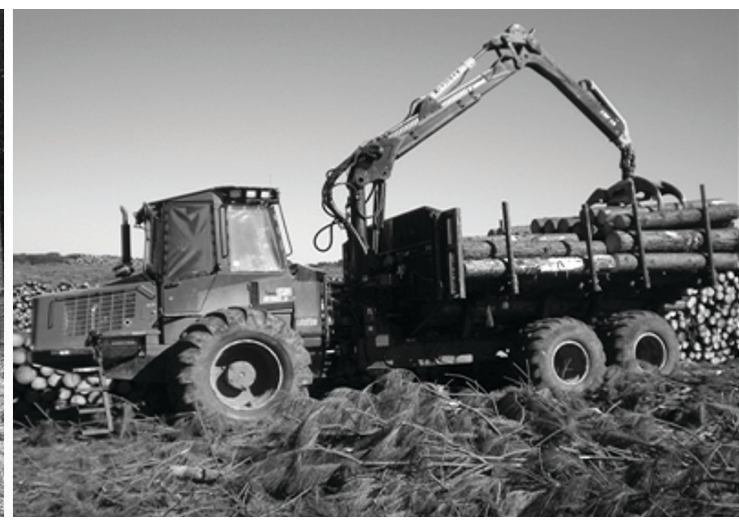

Figura 1. Harvester e forwarder utilizados na colheita de madeira.

Figure 1. Harvester and forwarder used in wood harvesting. 
$\left(\mathrm{kg}^{\mathrm{kg}}{ }^{-1}\right)$, Densidade (Ds), Porosidade total (Pt) e de aeração $(\mathrm{Pa})$ e Resistência do solo à penetração (RP). Todas as amostras foram identificadas e acondicionadas em embalagens plásticas herméticas, visando preservar as condições de campo, e transportadas para a realização das análises em laboratório.

Para a determinação da densidade foram coletadas amostras de solo com estrutura preservada, com uso de anéis volumétricos de $80 \mathrm{~cm}^{3}(5,0 \mathrm{~cm}$ de diâmetro $\times 5,1 \mathrm{~cm}$ de altura), com auxílio de um trado para amostras indeformadas (TAI) marca Soil Control nos quatro pontos equidistantes entre si dentro das parcelas e a profundidades de 0 a $15 \mathrm{~cm}, 15 \mathrm{a} 30 \mathrm{~cm}$ e 30 a $50 \mathrm{~cm}$.

Para obtenção da densidade, as amostras do solo foram pesadas para obtenção do peso úmido, secas em estufa a $105^{\circ} \mathrm{C}$ durante 24 horas e novamente pesadas para obtenção do peso seco, procedendo-se então à determinação da densidade por meio da Expressão 1 (Embrapa, 1997):

$$
D s=\frac{M s s}{V s}
$$

em que: $D s=$ densidade do solo $\left(\mathrm{g} . \mathrm{cm}^{-3}\right) ; M s s=$ massa do solo seco em estufa a $105^{\circ} \mathrm{C}(\mathrm{g})$; e $V s=$ volume do anel volumétrico $\left(\mathrm{cm}^{3}\right)$.

Para a determinação da porosidade total foi utilizado a metodologia proposta pela Embrapa (1997), conforme a Expressão 2, lembrando-se que a densidade de partículas (Dp) foi determinada pelo método do balão volumétrico.

$$
P t=\frac{D p-D s}{D p}
$$

em que: $P t=$ porosidade total $\left(\mathrm{m}^{3} \cdot \mathrm{m}^{-3}\right) ; D p=$ densidade de partículas do solo $\left(\mathrm{g} . \mathrm{m}^{-3}\right) ; D s=$ densidade do solo $\left(\mathrm{g} \cdot \mathrm{m}^{-3}\right)$.

A porosidade de aeração consiste no espaço poroso livre da solução do solo, ou seja, livre da fração volumétrica da água e essa, por sua vez, foi obtida por meio da umidade volumétrica com uso da Expressão 3:

$$
P a=P t-U v
$$

em que: $P A=$ porosidade de aeração $\left(\mathrm{m}^{3} \cdot \mathrm{m}^{-3}\right)$; $P t=$ porosidade total $\left(\mathrm{m}^{3} \cdot \mathrm{m}^{-3}\right) ; U v=$ umidade volumétrica do solo $\left(\mathrm{m}^{3} \cdot \mathrm{m}^{-3}\right)$.

A resistência do solo à penetração foi determinada por meio de um penetrógrafo da marca Soil Control, modelo SC-60, com uma haste de $600 \mathrm{~mm}$ de comprimento, 9,53 mm de diâmetro e cone de $129,3 \mathrm{~mm}^{2}$ de área de base. Os dados de resistência do solo à penetração foram obtidos próximos aos pontos distribuídos no interior das parcelas onde foram coletadas as amostras do solo. A resistência do solo à penetração (Mpa) foi medida por meio do Índice de Cone (IC) nos intervalos de $0 \mathrm{a}$ $15 \mathrm{~cm}, 15$ a $30 \mathrm{~cm}$ e 30 a $50 \mathrm{~cm}$ para cada tratamento, conforme metodologia da American Society of Agricultural Engineers - ASAE S 313 (ASAE, 1996).

\subsection{Análise estatística}

Os valores obtidos dos parâmetros físicos do solo foram submetidos à análise estatística, seguindo o padrão de experimento em delineamento inteiramente casualisado, com parcelas subdivididas. Foram comparadas as situações antes da derrubada das árvores, após a passada do harvester e após as passadas do forwarder nos diferentes pontos ao longo da trilha de extração. Todos os valores foram submetidos à análise de variância e as médias comparadas pelo teste de Tukey a $95 \%$ de probabilidade.

\section{RESULTADOS E DISCUSSÃO}

\subsection{Densidade do solo}

Na Tabela 2 são apresentados os valores médios de densidade do solo nas diferentes profundidades e tratamentos estudados. Como pode ser observado, em todos os tratamentos percebe-se a tendência de incremento na compactação com o aumento da profundidade do solo. Na condição inicial (AT), a camada superficial (0 a $15 \mathrm{~cm}$ ) apresentou uma

Tabela 2. Valores médios de densidade do solo $\left(\mathrm{g} . \mathrm{cm}^{-3}\right)$ causada pelo tráfego do harvester e do forwarder nas diferentes profundidades.

Table 2. Mean values of bulk density $\left(\mathrm{g} . \mathrm{cm}^{-3}\right)$ caused by traffic of harvester and forwarder in different classes of depth.

\begin{tabular}{cccc|}
\hline $\begin{array}{c}\text { Profundidade } \\
(\mathbf{c m})\end{array}$ & AT & HV & FW \\
\cline { 2 - 4 } 0 a 15 & $1,23 \mathrm{~A} \mathrm{a}$ & $1,28 \mathrm{~A} \mathrm{a}$ & $1,43 \mathrm{~A} \mathrm{a}$ \\
15 a 30 & $1,35 \mathrm{~A} \mathrm{a}$ & $1,38 \mathrm{~A} \mathrm{a}$ & $1,47 \mathrm{~A} \mathrm{a}$ \\
\hline 30 a 50 & $1,30 \mathrm{~A} \mathrm{a}$ & $1,47 \mathrm{~A} \mathrm{a}$ & $1,44 \mathrm{~A} \mathrm{a}$ \\
Média & 1,29 & 1,38 & 1,45 \\
\hline
\end{tabular}

Médias seguidas pelas mesmas letras maiúsculas não diferem entre tratamentos, médias seguidas pelas mesmas letras minúsculas não diferem estatisticamente entre profundidades pelo teste de Tukey ao nível de $5 \%$ de probabilidade. Fonte: elaborada pelos autores. 
densidade média de $1,23 \mathrm{~g} . \mathrm{cm}^{-3}$, enquanto as camadas de 15 a $30 \mathrm{~cm}$ e 30 a $50 \mathrm{~cm}$ apresentaram uma densidade média de 1,35 e 1,30 g. $\mathrm{cm}^{-3}$, respectivamente. Tal comportamento foi relatado por diversos autores, que afirmaram tratar-se de tendência natural do solo, devido à maior quantidade de matéria orgânica presente na camada superficial. Além disso, os menores valores de densidade observados na camada superficial pode ter relação direta com a atividade biológica (raízes, macro e micro fauna), ciclos de umedecimento e secagem, denominados agentes descompactadores.

Após o tráfego do harvester (HV), a camada superficial do solo $(0$ a $15 \mathrm{~cm}$ ) apresentou um incremento de $4,1 \%$ na compactação em relação à condição inicial (AT), com média de $1,28 \mathrm{~g} \cdot \mathrm{cm}^{-3}$, enquanto a camada subsuperficial teve um maior incremento $(13,1 \%)$, com média de $1,47 \mathrm{~g} . \mathrm{cm}^{-3}$. Entretanto, os valores obtidos não apresentaram diferença significativa entre tratamentos e profundidades, sendo possível notar que a camada subsuperficial do solo sofreu os maiores efeitos do tráfego das máquinas.

Após o tráfego do forwarder (FW), a camada superficial apresentou um incremento de $16,3 \%$ na compactação, com média de $1,43 \mathrm{~g} \cdot \mathrm{cm}^{-3}$, enquanto que, na camada de 15 a $30 \mathrm{~cm}$, o incremento foi de $8,9 \%$ e, na camada de 30 a $50 \mathrm{~cm}$, de $10,7 \%$. Geist et al. (1989) citam que o nível de compactação prejudicial ao desenvolvimento das plantas corresponde a um acréscimo acima de $15 \%$ na densidade do solo em relação ao valor inicial.

Portanto, pode-se dizer que a densidade do solo na camada superficial pode comprometer o desenvolvimento das plantas. Essa porcentagem de aumento da compactação na camada superficial, limitante ao desenvolvimento das plantas constitui, do ponto de vista técnico, a situação factível de se afrontar com os métodos de preparação de solo para o próximo ciclo de produção.

Segundo Reinert et al. (2006), um solo com 0,313 kg. $\mathrm{kg}^{-1}$ de argila apresenta densidade crítica em torno de 1,78 g.cm $\mathrm{cm}^{-3}$ e densidade restritiva de $1,84 \mathrm{~g} . \mathrm{cm}^{-3}$, podendo se afirmar que, apesar da tendência de aumento da densidade do solo devido ao tráfego das máquinas, verificou-se que a densidade crítica não foi atingida, com os valores observados nos tratamentos e profundidades estudados não apresentando diferença significativa pelo teste de Tukey ao nível de 5\% de probabilidade.

Os baixos valores de densidade do solo observados após as operações de colheita de madeira podem estar relacionados à permanência dos resíduos da colheita de madeira sobre o terreno, principalmente ao longo das trilhas de extração, os quais auxiliam na atenuação da compactação do solo causada pelo tráfego das máquinas.

\subsection{Porosidade total}

Na Tabela 3 são apresentados os resultados da porosidade total nas diferentes condições estudadas. $\mathrm{Na}$ condição antes do tráfego das máquinas (AT), a porosidade total não apresentou diferença significativa entre profundidades, variando de $0,534 \mathrm{~m}^{3} \cdot \mathrm{m}^{-3}$ na camada de 0 a $15 \mathrm{~cm}$ a $0,516 \mathrm{~m}^{3} \cdot \mathrm{m}^{-3}$ na camada de 30 a $50 \mathrm{~cm}$. Após o tráfego do harvester (HV), as camadas de 0 a $15 \mathrm{~cm}$ e 15 a $30 \mathrm{~cm}$ apresentaram uma redução de $3,9 \%$ e de $1,7 \%$ na porosidade, respectivamente, enquanto na camada mais profunda houve uma redução de 11,4\%. Após o tráfego do forwarder (FW), a camada superficial do solo apresentou uma redução de 14,0\%, seguida das demais camadas, com redução média de 12,9\% em relação à condição inicial do solo.

Os resultados obtidos não apresentaram diferença significativa na condição antes e após o tráfego das máquinas de colheita de madeira, porém permitiram evidenciar a elevada relação entre o comportamento da densidade e a porosidade total do solo.

Tabela 3. Valores médios de porosidade total $\left(\mathrm{m}^{3} \cdot \mathrm{m}^{-3}\right)$ depois do tráfego do harvester e do forwarder, nas diferentes classes de profundidade.

Table 3. Mean values of total porosity $\left(\mathrm{m}^{3} \cdot \mathrm{m}^{-3}\right)$ caused by traffic of harvester and Forwarder in different classes of depth.

\begin{tabular}{clcc} 
Profundidade & \multicolumn{3}{c}{ Tratamentos } \\
\cline { 2 - 4 }$(\mathbf{c m})$ & AT & HV & FW \\
\hline 0 a 15 & $0,534 \mathrm{~A} \mathrm{a}$ & $0,513 \mathrm{~A} \mathrm{a}$ & $0,459 \mathrm{~A} \mathrm{a}$ \\
15 a 30 & $0,521 \mathrm{~A} \mathrm{a}$ & $0,512 \mathrm{~A} \mathrm{a}$ & $0,453 \mathrm{~A} \mathrm{a}$ \\
30 a 50 & $0,516 \mathrm{~A} \mathrm{a}$ & $0,457 \mathrm{~A} \mathrm{a}$ & $0,450 \mathrm{~A}$ a \\
Média & 0,524 & 0,494 & 0,454 \\
\hline
\end{tabular}

Médias seguidas pelas mesmas letras maiúsculas não diferem entre tratamentos, médias seguidas pelas mesmas letras minúsculas não diferem estatisticamente entre profundidades pelo teste de Tukey ao nível de $5 \%$ de probabilidade. Fonte: elaborada pelos autores. 


\subsection{Porosidade de aeração}

Os valores de porosidade de aeração nas condições antes e após o tráfego das máquinas de colheita nas camadas do solo são apresentados na Tabela 4.

$\mathrm{Na}$ condição antes do tráfego das máquinas (AT), a porosidade de aeração foi decrescente em profundidade, variando de $0,217 \mathrm{~m}^{3} \cdot \mathrm{m}^{-3}$ na camada superficial a $0,149 \mathrm{~m}^{3} \cdot \mathrm{m}^{-3}$ na camada subsuperficial. Após o tráfego do harvester (HV), as camadas de $0 \mathrm{a}$ $15 \mathrm{~cm}$ e 15 a $30 \mathrm{~cm}$ apresentaram uma redução de $15,7 \%$ e $13,6 \%$, respectivamente, sendo que a camada de 30 a $50 \mathrm{~cm}$ apresentou uma redução menor $(4,7 \%)$ na porosidade de aeração.

Após o tráfego do forwarder (FW) foi possível verificar que a maior redução da porosidade de aeração ocorreu na camada superficial, correspondente a $70,0 \%$ em relação à condição anterior ao tráfego. Nas demais camadas, a redução foi decrescente, com $38,9 \%$ e $28,2 \%$ nas camadas de 15 a $30 \mathrm{~cm}$ e 30 a $50 \mathrm{~cm}$, respectivamente.

É importante ressaltar que, durante o processo de compactação, os poros maiores, responsáveis pela aeração do solo, diminuem e são substituídos por poros menores, responsáveis pela retenção de água. Isso ocorre porque os poros de maior diâmetro (macroporos) são menos resistentes e se deformam, formando poros de menor diâmetro, que são mais resistentes e suportam maior pressão.

O baixo valor de porosidade de aeração na camada superficial do solo após o tráfego do forwarder é uma

Tabela 4. Valores médios de porosidade de aeração $\left(\mathrm{m}^{3} \cdot \mathrm{m}^{-3}\right)$ depois do tráfego do harvester e do forwarder nas diferentes profundidades.

Table 4. Mean values of aeration porosity $\left(\mathrm{m}^{3} \cdot \mathrm{m}^{-3}\right)$ caused by traffic of harvester and forwarder in different classes of depth.

\begin{tabular}{clcc} 
Profundidade & \multicolumn{3}{c}{ Tratamentos } \\
\cline { 2 - 4 }$(\mathbf{c m})$ & \multicolumn{1}{c}{ AT } & HV & FW \\
\hline 0 a 15 & $0,217 \mathrm{~A} \mathrm{a}$ & $0,183 \mathrm{~A} \mathrm{a}$ & $0,065 \mathrm{~B} \mathrm{~b}$ \\
15 a 30 & $0,198 \mathrm{~A} \mathrm{a}$ & $0,171 \mathrm{~A} \mathrm{a}$ & $0,121 \mathrm{~A} \mathrm{a}$ \\
\hline 30 a 50 & $0,149 \mathrm{~A} \mathrm{a}$ & $0,142 \mathrm{~A} \mathrm{a}$ & $0,107 \mathrm{~A} \mathrm{a}$ \\
\hline Média & 0,188 & 0,165 & 0,097 \\
\hline
\end{tabular}

Médias seguidas pelas mesmas letras maiúsculas não diferem entre tratamentos, médias seguidas pelas mesmas letras minúsculas não diferem estatisticamente entre profundidades pelo teste de Tukey ao nível de 5\% de probabilidade. Fonte: elaborada pelos autores. situação preocupante, pois se trata da profundidade em que o sistema radicular das plantas necessita de condições apropriadas para o seu desenvolvimento inicial. Com um valor médio $0,065 \mathrm{~m}^{3} \cdot \mathrm{m}^{-3}$ de porosidade de aeração, nota-se a necessidade de uma intervenção mitigadora pois, segundo diversos autores, porosidade de aeração abaixo de $0,10 \mathrm{~m}^{3} \cdot \mathrm{m}^{-3}$ é considerada restritiva ao desenvolvimento das plantas, limitando a troca gasosa do solo com a atmosfera e tornando o ambiente anaeróbico para as raízes das plantas (Novak et al.,1992).

\subsection{Resistência do solo à penetração}

A Figura 2 apresenta o comportamento da resistência do solo à penetração nas condições antes do tráfego das máquinas, após os tráfegos do harvester e do forwarder. Como pode ser visto, nas condições antes do tráfego (Testemunha) e após o tráfego do harvester (HV) e do forwarder (FW), a resistência do solo à penetração apresentou valores abaixo do limite crítico ao desenvolvimento do sistema radicular das plantas nas camadas superficiais do solo, considerado por muitos autores acima de 2,0 MPa (Greacen \& Sands, 1980 ), e ao limite restritivo de 3,0 Mpa, proposto por Zou et al. (2000).

Entretanto, percebe-se um aumento na resistência do solo à penetração acima do limite crítico ao desenvolvimento das plantas após o tráfego das máquinas na camada do solo a partir de $10 \mathrm{~cm}$ de profundidade, devendo-se adotar medidas com vistas à redução da compactação do solo.

Os valores médios da resistência do solo à penetração nas três condições de tráfego são apresentados na

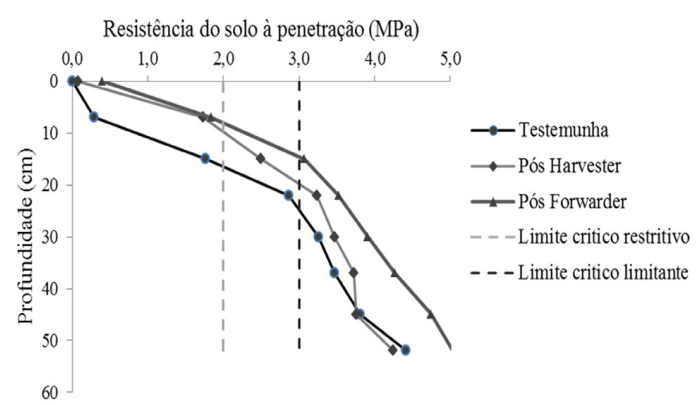

Figura 2. Resistência do solo à penetração antes e após tráfego do harvester e do forwarder nas diferentes profundidades.

Figure 2. Soil penetration resistance caused by traffic of harvester and forwarder in differents classes of depth. 
Tabela 5. Na condição antes do tráfego (AT), a camada de 0 a $15 \mathrm{~cm}$ apresentou baixa resistência $(0,70 \mathrm{Mpa})$, relacionada aos altos valores de porosidade total e de aeração dessa camada, enquanto que nas camadas de 15 a $30 \mathrm{~cm}$ e de 30 a $50 \mathrm{~cm}$ a média foi de 3,10 e 3,90 MPa, respectivamente, podendo o aumento da resistência à penetração em profundidade estar relacionado ao maior teor de argila presente nessas camadas do solo. Tal resultado está em concordância com os de Rosolem et al. (1999), que dizem que quanto maior a quantidade de argila, menor o tamanho médio dos poros e maior a resistência à penetração em uma dada densidade do solo.

Após o tráfego do harvester (HV), a camada superficial do solo apresentou maior incremento de resistência à penetração, com 104,3\% (1,43 Mpa), porém abaixo do valor crítico ao desenvolvimento das plantas. Tal resultado pode estar relacionado ao elevado teor de matéria orgânica nessa camada, situação que promove a manutenção das condições físicas dos solos, com aumento do limite de plasticidade e dificuldade no aumento da densidade e resistência à penetração.

Após o tráfego do forwarder percebe-se um aumento no incremento da compactação do solo em relação à testemunha na camada superficial, da ordem de $151,4 \%$, com valor médio de $1,76 \mathrm{MPa}$; seguido pela camada de 15 a $30 \mathrm{~cm}$, com incremento de $21,3 \%$ e média de 3,76 Mpa.

Houve uma diferença significativa entre os tratamentos apenas na camada de 0 a $15 \mathrm{~cm}$ de profundidade, situação que pode ser atribuída ao maior teor de

Table 5. Valores médios de resistência do solo à penetração (RP) antes e após o tráfego do harvester e do forwarder nas diferentes profundidades.

Table 5. Mean values of soil penetration resistance $\left(\mathrm{g} . \mathrm{cm}^{-3}\right)$ caused by traffic of harvester and forwarder in different classes of depth.

\begin{tabular}{cccc} 
Profundi- & \multicolumn{3}{c|}{ Tratamentos } \\
\cline { 2 - 4 } dade (cm) & AT & HV & FW \\
\hline 0 a 15 & $0,70 \mathrm{~A} \mathrm{~b}$ & $1,43 \mathrm{~B} \mathrm{~b}$ & $1,76 \mathrm{~B} \mathrm{~b}$ \\
\hline 15 a 30 & $3,10 \mathrm{~A} \mathrm{a}$ & $3,36 \mathrm{~B} \mathrm{a}$ & $3,76 \mathrm{~A} \mathrm{a}$ \\
\hline 30 a 50 & $3,90 \mathrm{~A} \mathrm{a}$ & $3,90 \mathrm{~B} \mathrm{a}$ & $4,66 \mathrm{~A} \mathrm{a}$ \\
\hline Média & 2,57 & 2,90 & 3,39 \\
\hline
\end{tabular}

Médias seguidas pelas mesmas letras maiúsculas não diferem entre tratamentos, médias seguidas pelas mesmas letras minúsculas não diferem estatisticamente entre profundidades pelo teste de Tukey ao nível de 5\% de probabilidade. Fonte: elaborada pelos autores. matéria orgânica nessa camada do solo. Entretanto, no geral percebe-se que o solo estudado, com exceção da camada superficial, encontrava-se compactado nas camadas mais profundas, sendo essa uma tendência natural, porém, quando somada às pressões exercidas pelo tráfego das máquinas, ela poderá causar restrições ao crescimento inicial das plantas.

\section{CONCLUSÃO}

Com base nas análises e discussão dos resultados, as principais conclusões foram:

a) O maior incremento da compactação ocorreu na camada superficial do solo, evidenciando a sensibilidade dessa camada ao tráfego intenso das máquinas de colheita de madeira;

b) Em geral, os níveis de compactação causados pelo tráfego do harvester e do forwarder não foram limitantes ao desenvolvimento das plantas;

c) A operação de extração de madeira com forwarder contribuiu para o incremento da compactação do solo, ocasionado pelas inúmeras passadas nas trilhas de extração;

d)O tráfego das máquinas de colheita de madeira no sistema de toras curtas acarretou um baixo nível de compactação, contribuído pela presença da camada de resíduos e teor de matéria orgânica presente na camada superficial do solo.

\section{AGRADECIMENTOS}

Agradecemos à empresa florestal, pela cessão da área de estudo e apoio, e ao $\mathrm{CNPq}$, pela bolsa de estudos.

\section{STATUS DA SUBMISSÃO}

Recebido: 12 jun., 2013

Aceito: 10 set., 2014

\section{AUTOR(ES) PARA CORRESPONDÊNCIA}

\section{Eduardo da Silva Lopes}

Departamento de Engenharia Florestal, Universidade Estadual do Centro-Oeste UNICENTRO, CEP 84500-000, Irati, PR, Brasil e-mail: eslopes@irati.unicentro.br 


\section{REFERÊNCIAS}

American Society of Agricultural Engineers - ASAE. Soil cone penetrometer. ASAE standards 1996: standards engineering practices data. St. Joseph: ASAE; 1996.

Camargo OA. Compactação do solo e desenvolvimento de plantas. Campinas: Fundação Cargil; 1983.

Dias MS Jr, Leite FP, Winter ME, Pires JVG. Avaliação quantitativa da sustentabilidade estrutural de um Latassolo Vermelho-Amarelo cultivado com eucalipto na região de Peçanha-MG. Revista Árvore 2003; 27(3): 343-349.

Dias MS Jr, Pierce FJ. Revisão de literatura: o processo de compactação solo e sua modelagem. Revista Brasileira de Ciência do Solo 1996; 20: 175-182.

Empresa Brasileira de Pesquisa Agropecuária - Embrapa. Manual de métodos de análise de solo. 2. ed. Rio de Janeiro: EMBRAPA; 1997.

Fenner PT. Compactação do solo. In: Machado CC, editor. Colheita Florestal. Viçosa: UFV; 2002.

Fernandes HC, Orlando RC, Lanças KP. Compactação do solo em relação à exploração florestal: influência do Forwarder e do Harvester. Engenharia na Agricultura 1997; 5(4): 276-280.

Geist JM, Hazard JW, Seidel KW. Assessing physical conditions of some Pacific Northwest Volcanic ash soils after forest harvest. Soil Science Society of America Journal 1989; 53(3): 946-950. http://dx.doi.org/10.2136/sssaj198 9.03615995005300030052x.

Greacen EL, Sands R. Compaction of forest soils: a review. Australian Journal of Soil Research 1980; 18(2): 163-189. http://dx.doi.org/10.1071/SR9800163.

Lanford BL, Stokes BJ. Comparison of two thinning systems: part 1- stand and site impacts. Forest Products Journal 1995; 45(4): 74-79.

Lopes SE, Fernandes HC, Machado CC, Rinaldi PCN, Silveira JCM. Compactação de um latossolo submetido ao tráfego do "Clambunk". Scientia Forestalis 2006; (72): 23-28.

Novak RK, Mantovani EC, Martyn PJ, Fernandes B. Efeito do tráfego de trator e da pressão de contato pneu/solo na compactação de um latossolo vermelho - escuro álico, em dois níveis de umidade. Pesquisa Agropecuária Brasileira 1992; 27(12): 1587-1595.

Reichert JM, Suzuki LEAS, Reinert DJ. Compactação do solo em sistemas agropecuários e florestais: identificação, efeitos, limites críticos e mitigação. In: Ceretta CA, Silva LS, Reichert JM, editors. Tópicos em Ciência do Solo. Viçosa: Sociedade Brasileira de Ciência do Solo; 2007.

Reinert DJ, Reichert JM, Veiga MV, Suzuki LEAS. Qualidade física dos solos. In: Reunião Brasileira de Manejo e Conservação do Solo e da Água [CD-ROM]; 2006; Aracaju. Aracaju: Sociedade Brasileira de Ciência do Solo; 2006.

Rosolem CA, Fernandez EM, Andreotti M, Crusciol CAC. Crescimento radicular de plântulas de milho afetado pela resistência do solo à penetração. Pesquisa Agropecuária Brasileira 1999; 34: 821-828.

Seixas F, McDonald TP, Stockes BJ, Raper RL. Effect of slash on forwarder soil compaction. In: Annual Meeting of the Council on Forest Engineering, 18.; 1995; Cashiers. Cashiers; 1995. p. 77.

Seixas F, Oliveira ED Jr, Souza CR. Efeito da camada de resíduos florestais na compactação do solo causada pelo transporte primário da madeira. Scientia forestalis 1998; 54: 9-16.

Seixas F, Souza CR. Avaliação e efeito da compactação do solo, devido à freqüência de tráfego, na produção de madeira de eucalipto. Revista Árvore 2007; 31(6): 1047 1052. http://dx.doi.org/10.1590/S0100-67622007000600009.

Silva VR, Reinert DJ, Reichert JM. Suscetibilidade à compactação de um Latossolo Vermelho-Escuro e de um Podzólico Vermelho-Amarelo. Revista Brasileira de Ciência do Solo 2000; 24(2): 239-249. http://dx.doi. org/10.1590/S0100-06832000000200001.

Soane BD, Van Ouwerkerk C. Soil compaction problems in world agriculture. In: Soane BD, Ouwerkerk C, editores. Soil compaction in crop production. Amsterdam: Elsevier; 1994. http://dx.doi.org/10.1016/B978-0-444-88286-8.50009-X.

Zou C, Sands R, Buchan G, Hudson I. Least limiting water range: A potential indicator of physical quality of forest soils. Australian Journal of Soil Research 2000; 38(5): 947-958. http://dx.doi.org/10.1071/SR99108. 